\title{
First record of the genus Tanaostigma (Hymenoptera, Chalcidoidea, Tanaostigmatidae) from the Afrotropical region with description of three new species
}

\section{Simon van Noort \& Robert S. Copeland}

To cite this article: Simon van Noort \& Robert S. Copeland (2020) First record of the genus Tanaostigma (Hymenoptera, Chalcidoidea, Tanaostigmatidae) from the Afrotropical region with description of three new species, Journal of Natural History, 54:9-12, 703-722, DOI: 10.1080/00222933.2020.1746426

To link to this article: https://doi.org/10.1080/00222933.2020.1746426

曲 Published online: 23 Sep 2020.

Submit your article to this journal $\asymp$

山ll Article views: 25

Q View related articles $\widetilde{ }$

View Crossmark data 


\title{
First record of the genus Tanaostigma (Hymenoptera, Chalcidoidea, Tanaostigmatidae) from the Afrotropical region with description of three new species
}

\author{
Simon van Noort $\mathbb{D}^{\mathrm{a}, \mathrm{b}}$ and Robert S. Copeland $\mathbb{D}^{\mathrm{c}, \mathrm{d}}$
}

aResearch and Exhibitions Department, South African Museum, Iziko Museums of South Africa, Cape Town, South Africa; 'Department of Biological Sciences, University of Cape Town, Rondebosch, South Africa; International Centre of Insect Physiology and Ecology (ICIPE), Nairobi, Kenya; dDepartment of Entomology, National Museum of Natural History, Smithsonian Institution, Washington, DC, USA

\begin{abstract}
The genus Tanaostigma is newly recorded from the Afrotropical region and three new species are described: Tanaostigma lasallei van Noort sp. nov. (South Africa), Tanaostigma mulu van Noort sp. nov. (Kenya) and Tanaostigma ukumbusho van Noort sp. nov. (Kenya). We provide comprehensive images of the holotypes and an illustrated identification key to the African species. New country distribution records are provided for Tanaostigmodes tambotis Prinsloo \& LaSalle, 1995. All images presented here as well as supplementary images and online keys are available on www.waspweb.org
\end{abstract}

www.zoobank.org/urn:Isid:zoobank.org:pub:61D1A59D-3702-480A-B146-73067C29CD82

\section{ARTICLE HISTORY}

Received 30 August 2019

Accepted 16 March 2020

Published online 23

September 2020

Published in print 23

September 2020

\section{KEYWORDS}

Africa; identification key; Kenya; new species; South Africa; taxonomy

\section{Introduction}

Tanaostigmatids are tropical or subtropical in distribution occurring in the Afrotropical, Australasian, Nearctic, Neotropical, Oriental and Palaearctic regions, with highest species richness in the New World (LaSalle 1987, 1997; Bouček 1988; Gibson 1993; Gupta and Joshi 2016; Noyes 2019). On a global basis 9 genera and 99 valid species are included in the family (Noyes 2019). The Afrotropical Tanaostigmatidae are poorly known, with two species in two genera described from the region. The monotypic Enigmencyrtus Trjapitzin, 1977 is represented by E. zambezei (Risbec 1955), a species only known from the holotype collected in Mozambique. Tanaostigmodes Prinsloo \& LaSalle 1995, is represented by T. tambotis Prinsloo \& LaSalle 1995, a gregarious phytophagous gall former on Spirostachys africana (Tamboti) (Euphorbiaceae), described from South Africa. Tanaostigma Howard, 1890 is currently largely known from the New World with a single Old World record from India (LaSalle 1987, 1997; Gupta and Joshi 2016). The genus is represented by 11 recognised Neotropical species, with two of these extending their range into the Nearctic region, and by a single Oriental species (LaSalle 1987, 1997; Gupta and Joshi 2016; Noyes 2019).

As part of a comprehensive, ongoing 27-year inventory survey of Afrotropical Hymenoptera, a single female of Tanaostigma was collected by the first author in the

CONTACT Simon van Noort svannoort@iziko.org.za

(C) 2020 Informa UK Limited, trading as Taylor \& Francis Group 
Zululand region of extreme northern Kwazulu-Natal, South Africa. Single females of two additional species were collected by the second author in Kenya as part of his inventory survey conducted in East Africa. Given the comprehensive long-term continuous sampling conducted in Africa by both authors these species are clearly rare, a phenomenon typical for the family (LaSalle 1987, 1997). We are aware that describing new species based on single specimens is not ideal, but given their rarity and clear morphological delimitation, we here describe these three new species and name two in memory of John La Salle, who passed away well before his time. We bestow this honour as recognition of John's immense contribution towards the field of chalcidoid systematics and entomology in general. We also provide an illustrated identification key to the African species. Online identification keys and all images presented here, as well as supplementary images, are available at www.waspweb.org.

\section{Methods}

Morphological terminology follows LaSalle (1987) and the Hymenoptera Anatomy Ontology (HAO: http://portal.hymao.org) (Seltmann et al. 2012). Surface sculpture description is based on Harris (1979) and Eady (1968). Measurements are given in micrometres.

Images were acquired at SAMC with a Leica LAS 4.9 imaging system, comprising a Leica ${ }^{\circledR}$ Z16 microscope (using either a $2 \mathrm{X}$ or $5 \mathrm{X}$ objective) with a Leica DFC450 Camera and $0.63 \mathrm{X}$ video objective attached. The imaging process, using an automated Z-stepper, was managed using the Leica Application Suite V 4.9 software installed on a desktop computer. Diffused lighting was achieved using a Leica LED5000 HDI dome. All images presented in this paper, as well as supplementary images, are available at www.waspweb.org.

Codens of depositories of specimens follow Arnett et al. (1993):

NMKE: National Museums of Kenya, Nairobi, Kenya (Curator: Laban Njoroge)

SAMC: Iziko South African Museum, Cape Town, South Africa (Curator: Simon van Noort) SANC: South African National Collection of Insects, Pretoria (Curator: Werner Strumpher)

\section{Results}

The three new African species all possess white squamiform setae, a generic synapomorphy placing them in the genus Tanaostigma. They are, however, collectively distinct from all other described Tanaostigma species and probably form their own species-group within the genus. In some respects, they are most similar to T. stanleyi La Salle, which is the only New World species to also have strong, modified setae on the fore wing, albeit present in a different configuration giving the wing a patterned appearance. This intricate pattern is very different to that created by the modified setae on the African species, where the setae either form a small patch beneath the marginal vein grading outwards into normal setae, or a transverse band of strong, dark setae. The African species also do not have all the antennal funicular segments wider than long, a character used by John LaSalle as one of the diagnostic attributes to define the genus (LaSalle 1987). The subsequently described Indian species Tanaostigma indica Gupta conforms to this character state in combination with laterally flattened funicle segments and is hence more similar to the Neotropical species than to the African species, an affinity also supported by 
the shared presence of medial incisions on the posterior margins of the tergites, which are absent in the African species. In terms of antennal morphology, the African species are most similar to the Neotropical species T. slossonae (Crawford), which also has funicular segments that are not flattened and are subequal in length. The scape of the three African species is not broad and flattened but does have a ventral expansion, which, however, is far more restricted than in the Neotropical species, being much smaller and only anteriorly situated. The African species do not have lateral glabrate (=glabrous) areas on the scutellum as do a number of the New World species. As is the case for T. stanleyi and $T$. indica, the stigmal vein is also curved and not perpendicular, contrasting with all other species, where the stigmal vein is almost straight and perpendicular to the marginal vein. We have accordingly modified the generic diagnosis to accommodate the additional character states exhibited by the African species.

\section{Tanaostigma Howard, 1890}

Tanaostigma Howard, 1890: 147-148. Type species Tanaostigma coursetiae Howard, 1890, by monotypy.

Trichencyrtus Ashmead, 1904: 291,292,392,495. Type species Trichencyrtus chapadae Ashmead, 1904, by original designation. Synonymy by LaSalle, 1987.

Diagnosis. Modified after LaSalle (1987) to incorporate the African species.

Females of the genus Tanaostigma are distinguished from other tanaostigmatids by the following unique characters: head and body with squamiform white setae (Figures $1(a, b), 3(a, b)$, and 5(a,b)); the Oriental species and most New World species have the funicular segments wider than long, except for T. slossonae, but in the three African species the first one or two segments are longer than wide or as wide as long; stigmal vein slender, straight, and perpendicular to the marginal vein in most New World species, but strongly curved and arising at an acute angle to marginal vein in the Neotropical species $T$. stanleyi, the Oriental $T$. indica and in all African species (Figures 1(f), 3(f), and 5(f)). In all New World and the Oriental species the scape is 1.5-2.5 times longer than wide with a flattened ventral expansion, however, this character is seen in many species of Tanaostigmodes Ashmead. In the African species, the scape is more elongate with the ventral expansion reduced and restricted to the distal half of the scape.

Males of New World species have 4-5 funicular rami, sometimes the frons has a transverse furrow halfway between torulus and median ocellus. Males are unknown for the Afrotropical and Oriental species.

Generic description. Modified from LaSalle (1987) to incorporate the African species.

Female. Colour usually mostly black to dark brown, sometimes with metallic tinge. Head usually with transverse white to yellow stripe on both face and lower frons, African clade and Oriental species without any stripes on head. Head and body usually with white squamiform setae.

Head surface sculpture usually reticulate to imbricate; scrobal impression shallow, without well-defined margin; inter-antennal projection present and small or absent. 

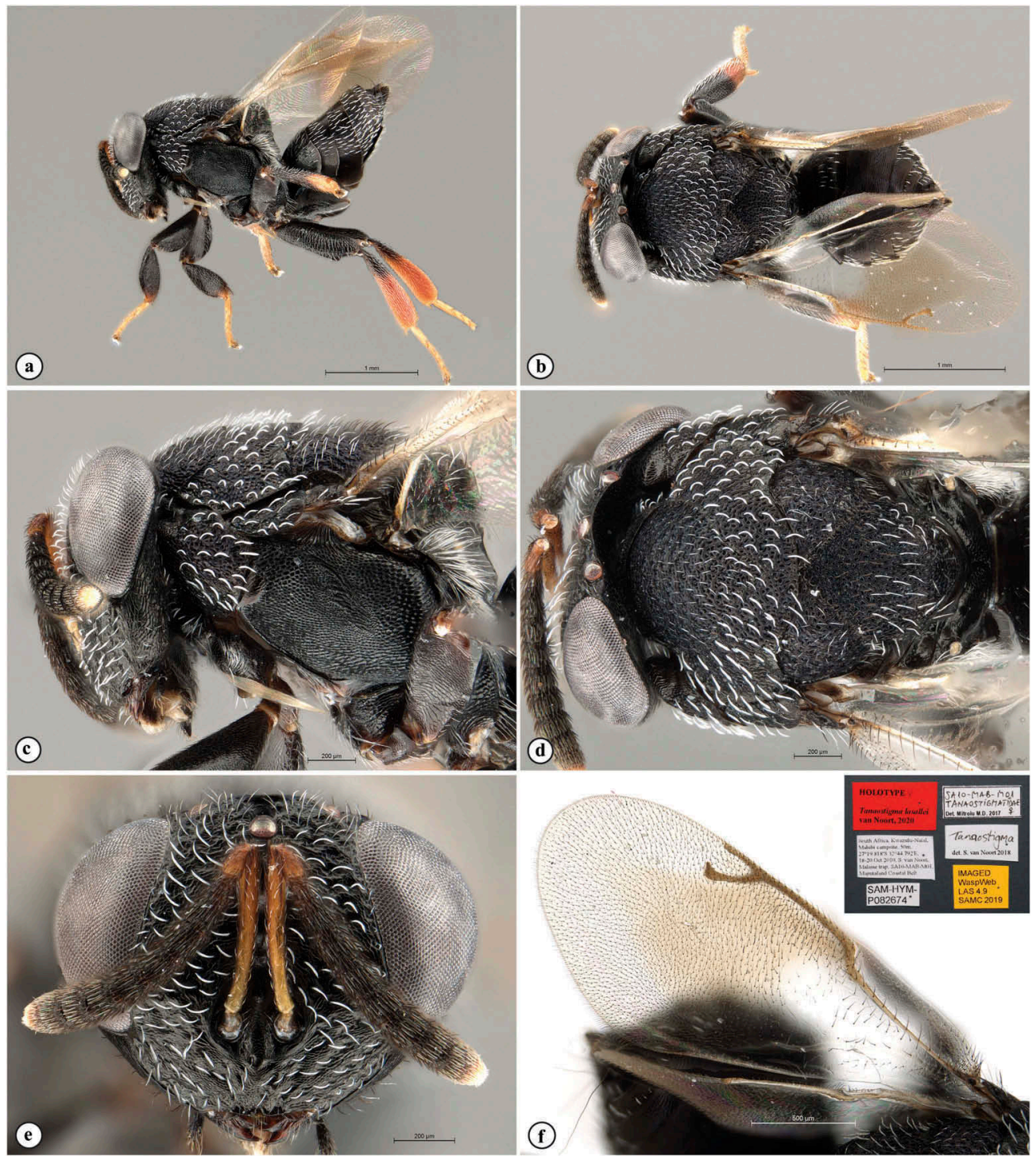

Figure 1. Tanaostigma lasallei Holotype female. (a) Habitus, lateral view (b) Habitus, dorsal view (c) Head and mesosoma, lateral view (d) Head and mesosoma, dorsal view (e) Head, anterior view (f) Wings (inset: data labels).

Subocular sulcus complete. Antenna with scape 1.5-2.5 times longer than wide, with flattened ventral expansion, which may be restricted to distal half. Funicular segments usually all wider than long, except in African clade where they are longer than wide or as wide as long.

Mesosoma dorsally usually reticulate. Notauli usually complete, but may be absent posteriorly in the African species. Scutellum often with lateral glabrate area, absent in African clade. Propodeum variable, often with one or more medial carinae. Mesopleuron usually reticulate. Middle tibia often with longitudinal carina on dorsal 
margin. Wings usually hyaline, with slender, delicate veins, but fore wing may have modified stouter setae that create patterns or transverse bands. Stigmal vein either straight and perpendicular to postmarginal vein or curved and at an acute angle to postmarginal vein.

Metasoma usually reticulate. Posterior margin of T2-T4 usually with medial incision, absent in African clade, except for indication on T2. Ovipositor slightly exerted.

Male (unknown in African species). Antenna with 4-5 long funicular rami. Funicular segments increasing in length distally. F6 longest funicular segment in species with five rami, shorter than F5 in species with four rami. Frons often with transverse furrow about halfway between torulus and median ocellus.

\section{Affinities}

Tanaostigma is still poorly defined, with the white squamiform setae, and wider than long and laterally compressed funicular segments proposed as synapomorphies defining the genus (LaSalle 1987). However, two species, T. glabrum and T. impilum, do not have squamiform setae, hypothesised to be a character state reversal (LaSalle 1987) and T. slossonae has funicular segments that are not flattened and are subequal in length. In terms of antennal morphology, the African species are most similar to this species, rendering the former character state of compressed antennal segments as of no use in defining the genus. LaSalle (1987) provides a detailed discussion of generic concepts and delimitation.

Distribution. Afrotropical, Nearctic, Neotropical and Oriental regions. Afrotropical records: Kenya, South Africa. Neotropical records: Argentina, Bahamas, Brazil, Colombia, Costa Rica, Cuba, Dominican Republic, Mexico, Puerto Rico, Trinidad and Tobago, Venezuela. Nearctic records: USA. Oriental record: India.

Biology of Tanaostigmatidae. Phytophagous, usually associated with galls, presumed to be the primary gall-former (LaSalle 1987, 2005). Exceptions include some Indian Tanaostigmodes species that are seed predators without gall formation (Lateef 1977; Lateef et al. 1985), and some Brazilian and Japanese Tanaostigmodes species develop as inquilines in cecidomyiid galls (Fernandes et al. 1987; LaSalle 1987), others are parasitoids of gall-forming cynipids (Tachikawa 1973, 1978; LaSalle and Noyes 1985; LaSalle 1987). Gall formers usually attack woody trees and shrubs of the family Fabaceae (= Leguminosae), a few attack species of Polygonaceae, Rhamnaceae, or Myrtaceae, forming galls on stems, leaves, seeds, or in flowers (usually in deformed ovaries) (LaSalle 1987; Gupta \& Joshi, 2016).

Host plant records for the Neotropical Tanaostigma species are as follows: Acacia constricta (T. stanleyi); Aeschynomene petraea var. madrensis (T. lobo); Canavalia ensiformis; Cratylia moelis, Inga species (T. gahani); Galactia striata; Galactia volubilis (T. slossonae); Haematoxylon brasiletto (T. haematoxyli); Haematoxylon campechianum (T. haematoxyli); Lonchocarpus latifolia (T. coursetiae); Machaerium robinifolium (T. bennetti); Machaerium (T. chapadae); Prosopis strombulifera (T. albosquamatum); Willardia mexicana (T. coursetiae) (LaSalle, 1987); the Oriental species $T$. indica was collected from a container containing Millettia (= Pongamia) pinnata (L.) Panigrahi (Fabaceae) leaves infested with galls (Gupta and Joshi 2016). Biology of the Afrotropical species is unknown. 
Key to Afrotropical species of Tanaostigma

(a)

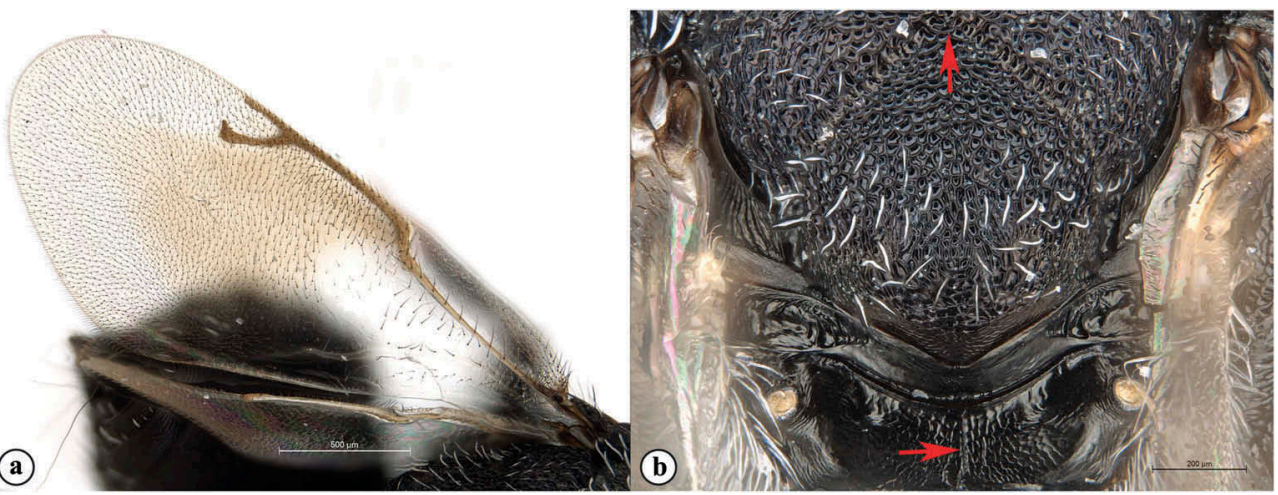

1. Fore wing with broad brown central infuscation (a); propodeum with complete medial longitudinal carina (b); axillar grooves meet at trans-scutellar sulcus (b); hind femur and fore tibia all black T. lasallei sp. nov.
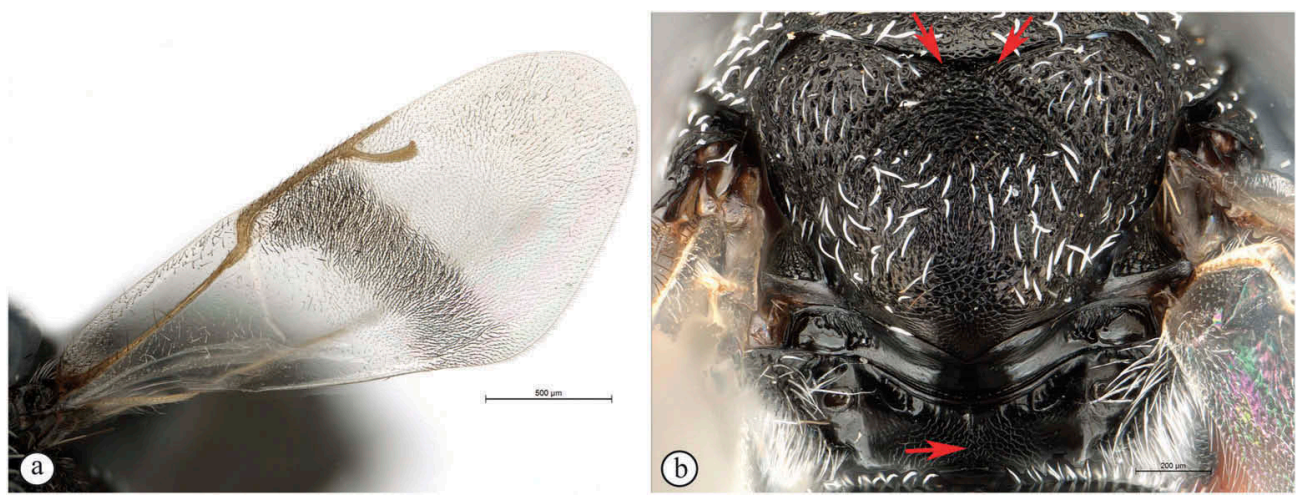

- Fore wing with narrow transverse band of dark setae (a); propodeum either without carina or with the medial longitudinal carina only present anteriorly for a very short distance (b); axillar grooves meet trans-scutellar sulcus independently (b); hind femur and fore tibia with distal end orangish-brown
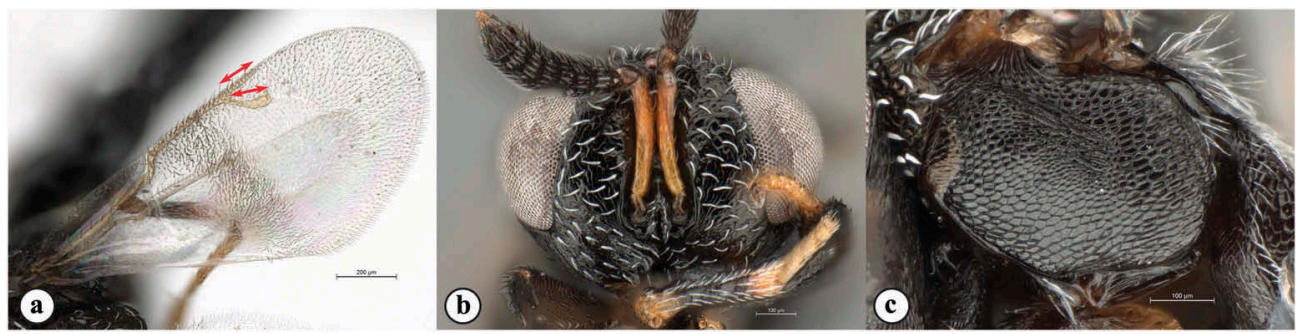

2. Fore wing band with fewer, more pale, and less densely distributed setae (a); fore wing twice as long as wide (a); postmarginal vein as long as stigmal vein (a); squamiform white setae stouter and individually more widely spaced on head (b) and other areas of the body; mesopleuron with coarse reticulate sculpturing (c); 
metanotal trough with three large metanotal fovea, not extending medially beyond small central metanotal fovea T. mulu sp. nov.
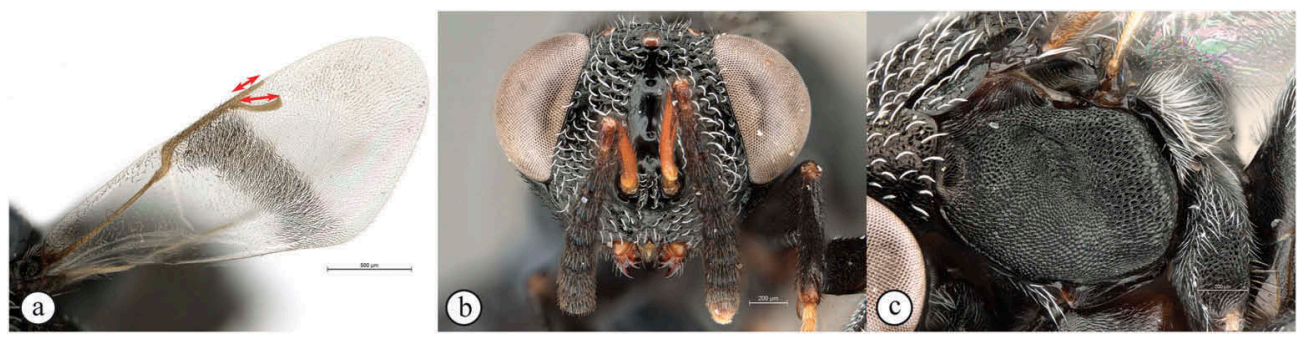

- Fore wing band with numerous dark, densely distributed setae (a); fore wing 2.5 times as long as wide (a); postmarginal vein shorter than stigmal vein (a); squamiform white setae more elongate and densely distributed on head (b) and other areas of the body; mesopleuron with finer, more numerous reticulate sculpturing (c); metanotal trough with a single large metanotal fovea laterad of small central fovea, with narrow elongate fovea anteriorly situated, with three pit-like fovea present medially of central metanotal fovea.

T. ukumbusho sp. nov.

\section{Tanaostigma lasallei van Noort sp. nov}

(Figures 1(a-f), 2(a-f))

Holotype $q$ (deposited in SAMC), point mounted: SOUTH AFRICA, Kwazulu-Natal, Mabibi

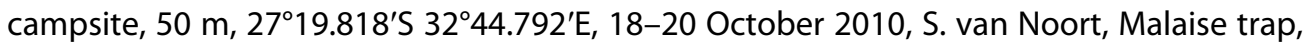
SA10-MAB-M01, Maputaland Coastal Belt, SAM-HYM-P082674, imaged WaspWeb, LAS 4.9, SAMC 2019.

\section{Description of female}

Size and colour. Length $3.3 \mathrm{~mm}$. Head and body black with extensive areas of the head, mesosoma, and metasoma covered with white squamiferous setae, absent on mesopleura, antero-medial portion of mesoscutum, anterior half of scutellum, medial dorsal and anterior ventral areas of metasoma. Scape and pedicel orange-brown, anelli and first funicle segment dark brown grading into black for rest of flagellar segments except for last two club segments, which are orange-yellow. Distal two-thirds of hind tibiae orange. All tarsi yellow-orange, as is distal third of meso-tibia. Finer, white setae present on legs.

Head (Figure 1(e)) 1.3 times wider than high. Lateral ocellus closer to eye margin than to median ocellus (OOL:LOL: 0.37 ), situated directly adjacent to sharp occipital carinal crest, which curves inwards towards median ocellus. Scrobal impression shallow, glabrate. Inter-antennal projection small. Genal sulcus complete. Head sculpture elongate reticulate on face grading to imbricate on frons, with evenly dispersed white squamiferous setae present on face and frons, grading into normal white setae on vertex, setae largely absent on posterior of head including genae posterior of genal sulcus. Mandible tridentate (Figure 2(a)). Antenna (Figures 2(a,b)) with scape 4.7 times longer than wide, with flattened ventral expansion present on distal half. Pedicel 1.5 times longer than wide. 

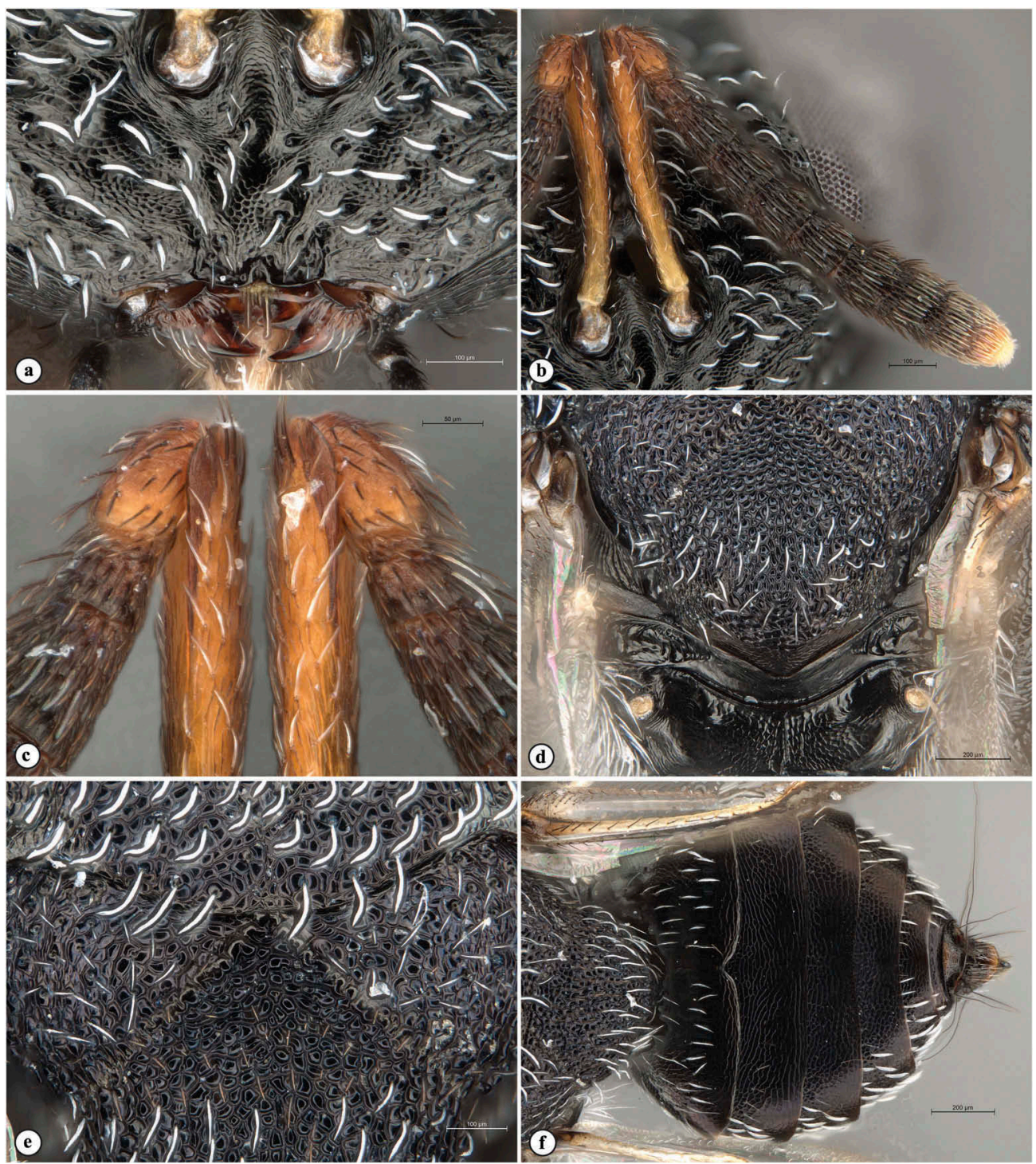

Figure 2. Tanaostigma lasallei Holotype female. (a) Clypeus and mandibles (b) Antenna (c) Pedicel and anelli (d) Scutellum, metanotum and propodeum (e) Trans-scutellar suture (f) Metasoma, dorsal view.

Two anelli, first about half as long as, and slightly narrower than second. First funicular segment longer than wide, F2-F4 as wide as long, F5-F6 wider than long, not laterally compressed. Club 1.4 times longer than wide, proximally as broad as preceding funicle segment, narrowing to tip.

Mesosoma dorsally minutely reticulate, punctiferous where setae present, covered with white squamiferous setae, except for mesoscutum anterior of notauli and axillae which have small, fine white setae. Notauli complete but indistinct posteriorly, meeting before trans-scutellar articulation. Scutellum (Figure 1(d)) without lateral glabrate area, devoid of white setae in anterior third, replaced by small, fine brown setae. Propodeum (Figure 2(d)) 
laterally glabrate to medially reticulate with complete medial carina; metanotal trough with two large metanotal fovea laterad of central smaller fovea, with narrow elongate fovea anteriorly situated, extending medially beyond central fovea. Mesopleuron (Figure $1(c)$ ) dorsally reticulate, ventrally elongate reticulate, medially finely reticulate, without setae. Sternopleural suture fused with mesopleural suture. Metapleuron covered with a dense cluster of long white setae (Figure 1(c)); which extend to the proximal dorsal surface of the hind coxa. Leg segments laterally flattened; all tibiae with sharp dorsal margin. Hind femora with a distal ventral angulate extension, curving inwards to end of femur; hind tibiae with a proximal dorsal carina. Wings hyaline, except for fore wing (Figure 1(f)) which has a medial infuscate patch extending from marginal and stigmal veins halfway towards apical and ventral margins in an axe shape; larger, modified, dark setae present below marginal vein grading outwards into normal setae; small triangular patch of larger more widely dispersed setae present directly below submarginal vein, adjacent to glabrous area. Venation dark brown, submarginal vein lighter. Stigmal vein strong, distinctly curved, longer than post-marginal vein. Fore wing marginal fringe present apically, extending ventrally to anal angle. Costal cell: marginal vein: stigmal vein: postmarginal vein $=50: 32: 15: 12$.

Metasoma (Figure 2(f)) with elongate reticulate surface sculpture; T2 with transverse rows of scattered setae, T3-T5 without setae medially; T6 with a row of setae anteriorly, T7 with setae laterally. Posterior margin of $\mathrm{T} 2$ with shallow medial invagination; faint medial line present; posterior margin of T3-T7 straight, without medial incision, or medial line. Ovipositor short. Each pygostyle with four setae, two extremely elongate, half as long as metasoma, the remaining pair half this length.

Male. Unknown.

Diagnosis. Tanaostigma lasallei is distinguished from other Tanaostigma by having an infuscate area on the fore wing (Figure 1(f)). The modified setae are restricted to a small patch below the marginal vein and do not contribute to the colour pattern on the wing. Presence of modified setae is shared with the Neotropical species T. stanleyi, which however has a patterned appearance as a result, and the other two African species where the setae form an obvious dark transverse band. The stigmal vein is strongly curved (Figure 1(f)). Scutellum lacks lateral glabrate area (Figure 1(d)); and posterior margin of T2-T4 without medial incision (Figure 2(f)). All three of these character states are shared with the other two African species, which have a very different wing pattern, and with the Neotropical T. stanleyi, which, in contrast to the black African species, is strikingly coloured with pink, orange and white areas on the pleural regions and face. The remaining species of Tanaostigma have a straight stigmal vein, glabrate areas on the scutellum and medial incisions on the metasomal tergites. Notauli of $T$. lasallei are complete, but indistinct posteriorly, whereas the other two African species have incomplete notauli and the New World and Oriental species have distinct, complete notauli.

Affinities. This species shares antennal morphology with the other two African species, and this is most similar to the Neotropical species, T. slossonae, which also has funicular segments that are not flattened, but which are subequal in length. The fore wing has only 
a small patch of weakly modified setae below the marginal vein, and does not have the extensive modified setae on the fore wing of the other two African species, but this shared character state suggests a possible relationship with the Neotropical species, $T$. stanleyi.

Etymology. The species is named in memory of John LaSalle. Genitive case.

Distribution. South Africa. Only known from Kwazulu-Natal Province.

Biology. Unknown.

Habitat. Coastal bushveld/grassland.

\section{Tanaostigma mulu van Noort sp. nov}

(Figures 3(a-f), 4(a-f))

Holotype $q$ (deposited in NMKE), point mounted: KENYA, Eastern Prov., Mulu Musingila Farm, $689 \mathrm{~m}, 2.11412^{\circ} \mathrm{S} .38 .23989^{\circ} \mathrm{E}$, Malaise trap, farmland near small, seasonally wet area, 11-25 December 2017, R. Copeland, Tanaostigma, 6904-23, ICIPE 10307, USNMENT-01448450, imaged WaspWeb, LAS 4.9, SAMC 2019.

\section{Description of female}

Size and colour. Length $1.7 \mathrm{~mm}$. Head and body black with extensive areas of the head, mesosoma, and metasoma covered with white squamiferous setae, absent on mesopleura, antero-medial portion of mesoscutum, anterior half of scutellum, medial dorsal and anterior ventral areas of metasoma. Scape orange-brown, pedicel brown, flagellar segments black except for last club segment, which is orange-yellow. Distal two-thirds of hind tibiae yellow-orange. All tarsi yellowish-orange, as are distal quarter of pro and mesotibiae, and apex of hind femora. Finer, white setae present on legs.

Head (Figure 1(e)) 1.35 times wider than high. Lateral ocellus closer to eye margin than to median ocellus (OOL:LOL: 0.66), situated directly adjacent to sharp occipital carinal crest, which curves inwards towards median ocellus. Scrobal impression shallow, glabrate. Inter-antennal projection small. Genal sulcus complete. Head sculpture elongate reticulate on face grading to imbricate on frons, with evenly dispersed white squamiferous setae present on face and frons, grading into more normal white setae on vertex, setae largely absent on posterior head including genae posterior of genal sulcus. Mandible not visible (obscured by legs). Antenna (Figure 3(b,c)) with scape 3.6 times longer than wide, with flattened ventral expansion present on distal half. Pedicel 1.4 times longer than wide. Two anelli, first about half as long as, and slightly narrower than second. First two funicular segments as wide as long, remaining segments wider than long, not laterally compressed. Club 1.5 times longer than wide, proximally almost as broad as preceding funicle segment, gradually narrowing to tip.

Mesosoma dorsally minutely reticulate, punctiferous where setae present, covered with white squamiferous setae, except for mesoscutum anterior of notauli and axillae which have small, fine white setae. Notauli incomplete, absent posteriorly. Scutellum (Figures 3(d) and 4(d)) without lateral glabrate area, devoid of white setae in anterior third. Propodeum (Figure 4(d)) laterally glabrate, medially reticulate with no medial 

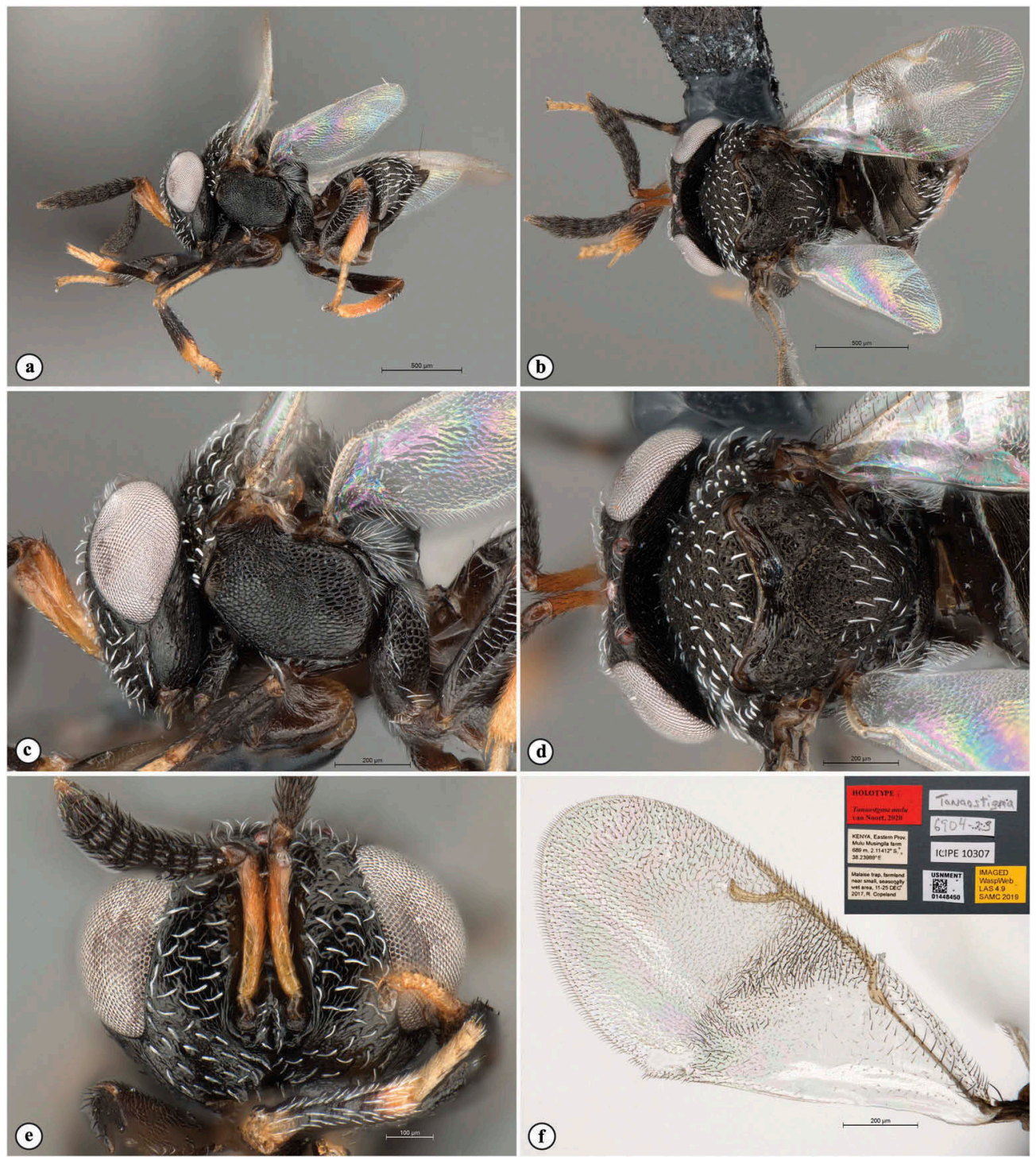

Figure 3. Tanaostigma mulu Holotype female. (a) Habitus, lateral view (b) Habitus, dorsal view (c) Head and mesosoma, lateral view (d) Head and mesosoma, dorsal view (e) Head, anterior view (f) Wings (inset: data labels).

carina; metanotal trough with three large metanotal fovea, not extending medially beyond small central metanotal fovea. Mesopleuron (Figure $3(c)$ ) dorsally with reticulate surface sculpture, ventrally with elongate reticulate sculpture, medially finely reticulate, without setae. Sternopleural suture fused with mesopleural suture. Metapleuron covered with a dense cluster of long white setae (Figure 3(c)); which extend to the proximal dorsal surface of the hind coxa. Leg segments laterally flattened; all tibiae with sharp dorsal margin. Hind femora with a distal ventral angulate extension, curving inwards to end of femur; hind tibiae with a proximal dorsal carina. Wings hyaline; fore wing (Figure 

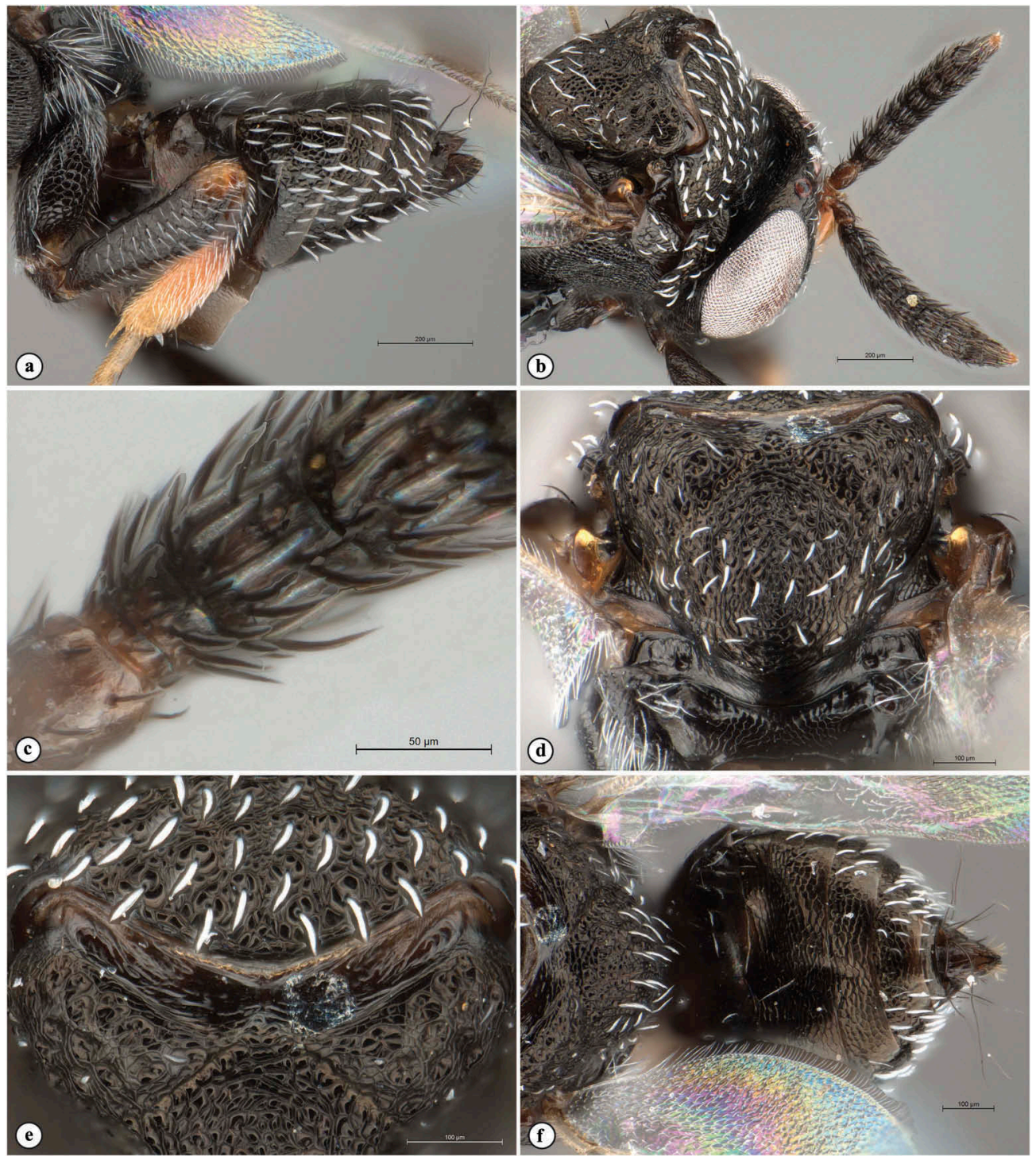

Figure 4. Tanaostigma mulu Holotype female. (a) Metasoma, lateral view (b) Mesosoma, head and antenna (c) Pedicel and anelli (d) Scutellum, metanotum and propodeum (e) Trans-scutellar suture (f) Metasoma, dorsal view.

3(f)) with transverse band of dark, modified setae; fore wing twice as long as wide. Venation light yellowish-brown. Stigmal vein strong, distinctly curved, as long as postmarginal vein. Fore wing marginal fringe present apically, extending ventrally to anal angle. Costal cell: marginal vein: stigmal vein: postmarginal vein = 14:9:4:4.

Metasoma (Figure 4(f)) elongate reticulate; T1 with transverse rows of scattered setae, T3-T5 without setae for most of the dorsal medial surface; T6 with two rows of setae, only absent on midline. Posterior margin of T2 with shallow medial invagination; posterior margin of T3-T7 straight, without medial incision or medial line. Ovipositor short. Each 
pygostyle with four setae, two extremely elongate, half as long as metasoma, the remaining pair half this length.

Male. Unknown.

Comments. The trans-scutellar sutural membrane is exposed and expanded in the specimen of $T$. mulu giving it a very different mesosomal appearance than the two other species that have the potential articulation between the mesoscutum and scutellum in the normal closed position.

Diagnosis. Tanaostigma mulu is distinguished from other Tanaostigma by having a band of strongly modified dark setae on the fore wing (Figure 3(f)), except for T. umkumbusho, which has a much more obvious dark transverse band, a longer stigmal vein and more elongate fore wing. Presence of modified setae is shared with the Neotropical species T. stanleyi, which, however, has a patterned appearance. The stigmal vein is strongly curved (Figure 3(f)). Notauli incomplete, absent posteriorly, a character state shared with T. ukumbusho, all other species have complete notauli. The scutellum lacks the lateral glabrate area (Figure 4(d)); and posterior margin of T2-T4 without medial incision (Figure 2(f)). All three of these character states are shared with the other two African species, and the Neotropical T. stanleyi, which in contrast to the black African species, is strikingly coloured with pink, orange and white areas on the pleural regions and face. The remaining species of Tanaostigma have a straight stigmal vein, glabrate areas on the scutellum and medial incisions on the metasomal tergites.

Affinities. Based on the putative morphological synapomorphy of modified setae on the fore wing $T$. mulu is most closely related to $T$. ukumbusho, these two species probably forming a monophyletic clade, sister to the next most similar species, T. lasallei, which, however, only has a small patch of weakly modified setae below the marginal vein. All three of these African species are possibly related to the Neotropical $T$. stanleyi, which also has extensive patches of modified fore wing setae, albeit in a different patterned configuration. Like the other African species, T. mulu does not have flattened or widened funicular segments suggesting a similarity to the Neotropical species, $T$. slossonae, which also has funicular segments that are not flattened, but which are subequal in length.

Etymology. The species epithet 'mulu' is Kiswahili (a widely spoken East African language) for 'heap', referring to the heaped or humped appearance of the mesosoma in lateral view, and is also the first part of the name of the farm encompassing the type locality. Noun in apposition.

Distribution. Kenya. Known only from Eastern Province.

Biology. Unknown.

Habitat. Farmland near small, seasonally wet area. 


\section{Tanaostigma ukumbusho van Noort sp. nov}

(Figures 5(a-f), 6(a-f))

Holotype $q$ (deposited in NMKE), point mounted: KENYA, Coast Prov., Boni Forest, $29 \mathrm{~m}$ ASL, $1.84752^{\circ} \mathrm{S} 40.69307^{\circ} \mathrm{E}, 6 \mathrm{~m}$ Malaise trap in open canopy Forest, 6-18 June 2013, J. Bukhebi \& R. Copeland, ICIPE 10462, Tanaostigma, imaged WaspWeb, LAS 4.9, SAMC 2019.
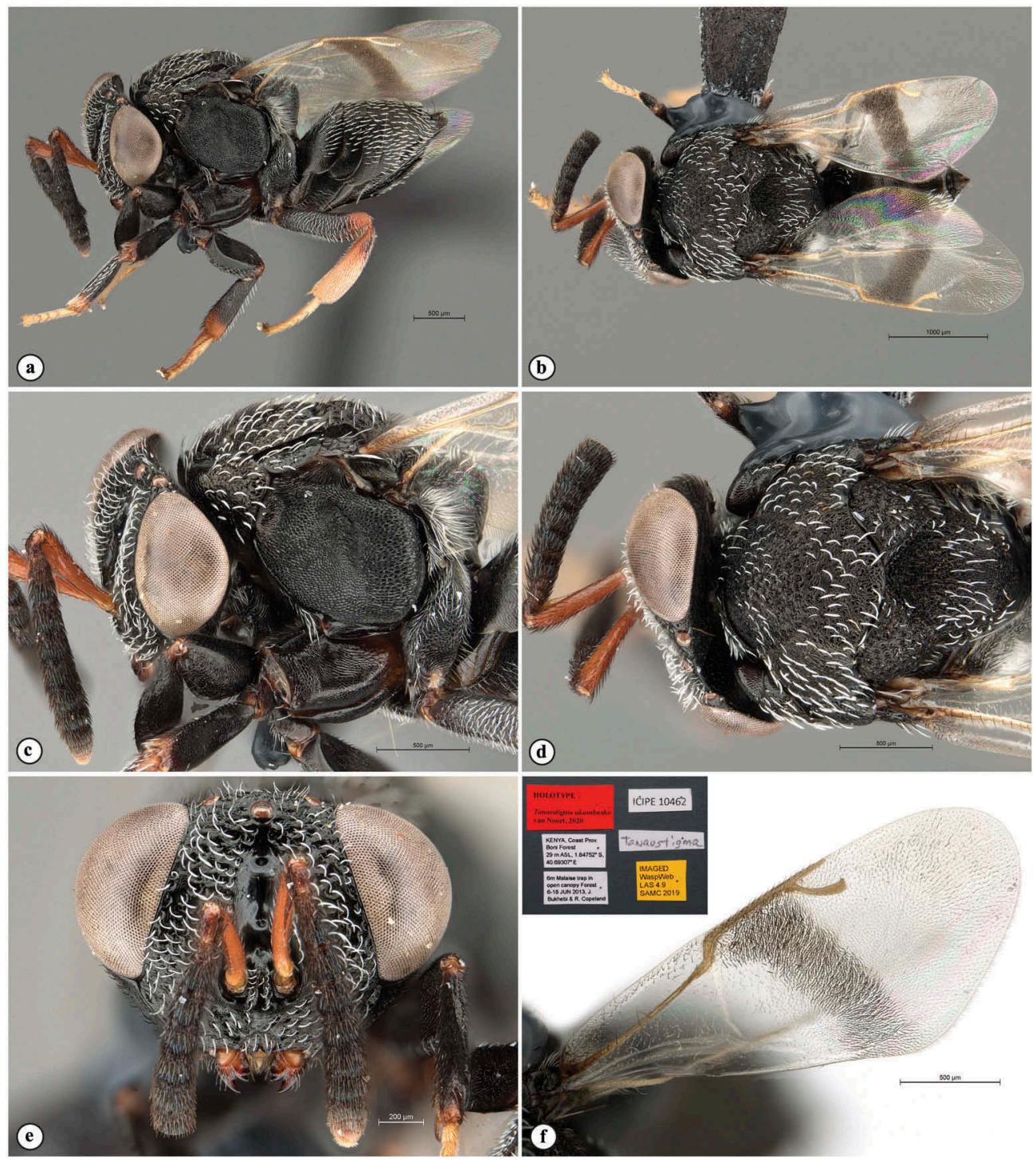

Figure 5. Tanaostigma ukumbusho Holotype female. (a) Habitus, lateral view (b) Habitus, dorsal view (c) Head and mesosoma, lateral view (d) Head and mesosoma, dorsal view (e) Head, anterior view (f) Wings (inset: data labels). 

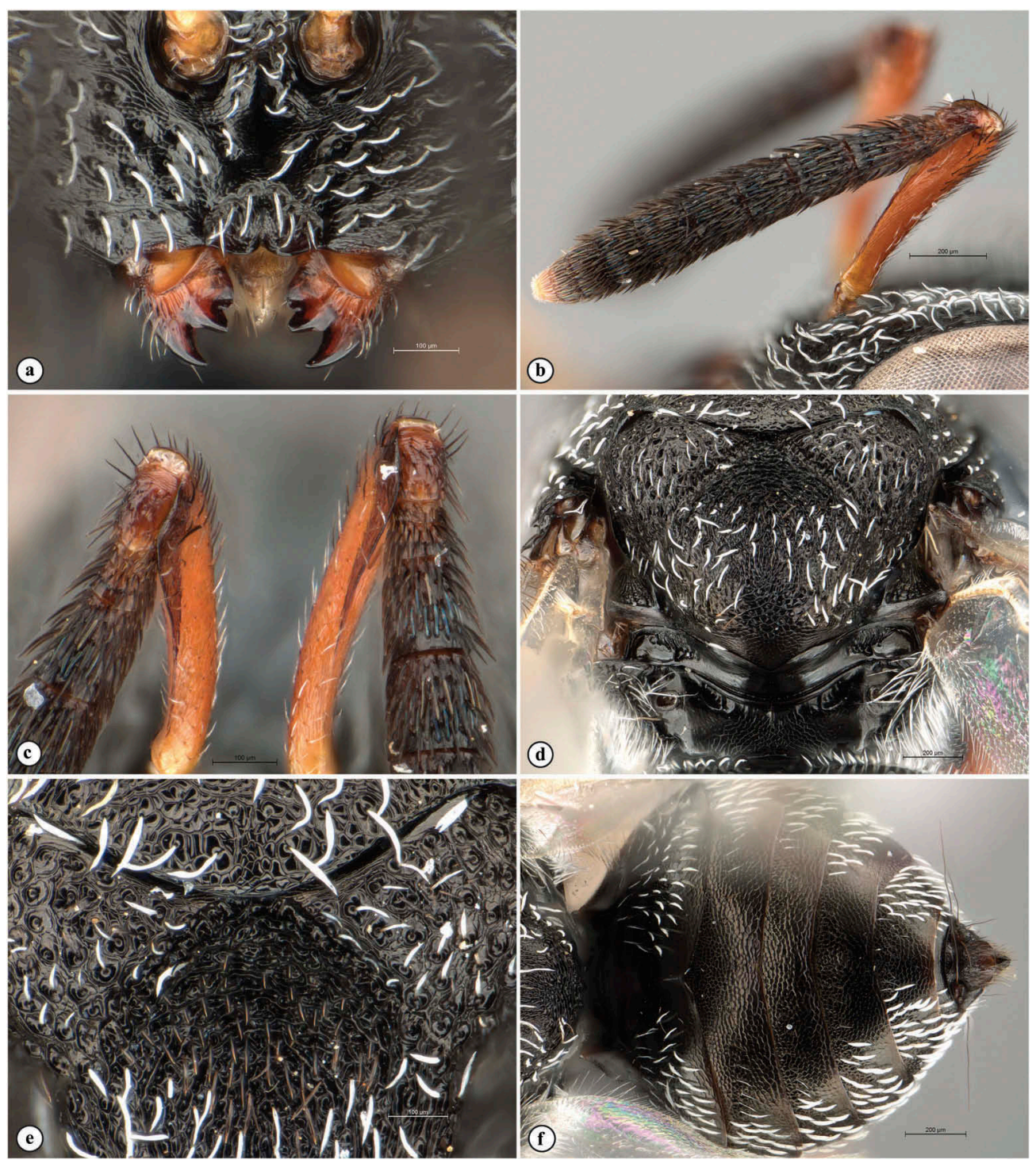

Figure 6. Tanaostigma ukumbusho Holotype female. (a) Clypeus and mandibles (b) Antenna (c) Pedicel and anelli (d) Scutellum, metanotum and propodeum (e) Trans-scutellar suture (f) Metasoma, dorsal view.

\section{Description of female}

Size and colour. Length $3.6 \mathrm{~mm}$. Head and body black with extensive areas of the head, mesosoma, and metasoma covered with white squamiferous setae, absent on mesopleura, medial portion of mesoscutum, anterior half of scutellum, medial dorsal and anterior ventral areas of metasoma. Scape and pedicel orange-brown, anelli and first funicle segment dark brown, grading into black for rest of flagellar segments except for last club segment, which is orange-yellow. Hind tibiae yellow-orange, except for proximal 
dorsal patch which is dark brown. All tarsi yellow-orange, as are distal quarter of pro and meso-tibiae, and apex of hind femora. Finer white setae present on legs.

Head (Figure 5(e)) 1.44 times wider than high. Lateral ocellus closer to eye margin than to median ocellus (OOL:LOL: 0.42), situated directly adjacent to sharp occipital carinal crest, which curves inwards towards median ocellus. Scrobal impression shallow, glabrate. Interantennal projection small. Genal sulcus complete. Head elongate reticulate on face grading to imbricate on frons, with evenly dispersed white squamiferous setae present on face and frons, grading into more normal white setae on vertex, setae largely absent on posterior head including genae posterior of genal sulcus. Mandible tri-dentate (Figures 5(e) and 6(a)). Antenna (Figure $6(b, c)$ ) with scape 3.85 times longer than wide, with flattened ventral expansion present on distal half. Pedicel 1.4 times longer than wide. Two anelli, first about half as long as, and slightly narrower than second. First funicular segment longer than wide, F2-F3 as wide as long, remaining segments wider than long, not laterally compressed. Club 1.4 times longer than wide, proximally almost as broad as preceding funicle segment, gradually narrowing to tip.

Mesosoma dorsally minutely reticulate, punctiferous where setae present, covered with white squamiferous setae, except for medial mesoscutum anterior of notauli, and lateral areas of axillae. Notauli incomplete, absent posteriorly. Scutellum (Figures 5(d) and 6(d,e)) without lateral glabrate area, devoid of white setae in anterior third, but with fine, brown setae. Propodeum (Figure 6(d)) laterally glabrate, medially reticulate with short medial carina anteriorly situated; metanotal trough with a single large metanotal fovea laterad of small central fovea, with narrow elongate fovea anteriorly situated, with three pit-like fovea present medially of central metanotal fovea. Mesopleuron (Figure 5(c)) dorsally reticulate, ventrally elongate reticulate, medially finely reticulate, without setae. Sternopleural suture fused with mesopleural suture. Metapleuron covered with a dense cluster of long white setae (Figure 5(c)), which extend to the proximal dorsal surface of the hind coxa. Leg segments laterally flattened; all tibiae with sharp dorsal margin. Hind femora with a distal ventral angulate extension, curving inwards to end of femur; hind tibiae with a proximal dorsal carina. Wings hyaline; fore wing (Figure 5(f)) with narrow transverse band of black, densely distributed, modified setae; fore wing 2.5 times as long as wide. Venation light yellowish-brown. Stigmal vein strong, distinctly curved, longer than post-marginal vein. Fore wing marginal fringe present apically, extending ventrally to anal angle. Costal cell: marginal vein: stigmal vein: postmarginal vein $=15: 9: 4: 3$.

Metasoma (fig.) elongate reticulate; T1 with transverse rows of scattered setae, absent medially, T3-T5 without setae for most of the dorsal medial surface; T6 with three interspersed rows of setae, only absent on midline. Posterior margin of T2 with shallow medial invagination; medial line present; posterior margin of T3-T7 straight, without medial incision or medial line. Ovipositor short. Each pygostyle with four setae, two extremely elongate, half as long as metasoma, the remaining pair half this length.

Male. Unknown.

Diagnosis. Tanaostigma ukumbusho is distinguished from other Tanaostigma by having a transverse band of strongly modified, dense, black setae on the fore wing, extending from the marginal vein to the anal angle (Figure 5(f)), similar to T. mulu, which, however, 
has a much weaker transverse band, a shorter stigmal vein and less elongate fore wing (compare Figure 3(f)). Tanaostigma ukumbusho has a stigmal vein almost $1.4 \mathrm{X}$ longer than the post-marginal vein and a fore wing 2.5X longer than wide (Figure 5(f)). Presence of modified setae is shared with the Neotropical species $T$. stanleyi, which however has a patterned appearance. Notauli incomplete, absent posteriorly, a character state shared with T. mulu, all other species have complete notauli. The stigmal vein is strongly curved (Figure 5(f)). The scutellum lacks the lateral glabrate area (Figure 6(d)); and posterior margin of T2-T4 without medial incision (Figure 2(f)). All three of these character states are shared with the other two African species and the Neotropical T. stanleyi, which in contrast to the black African species, is strikingly coloured with pink, orange and white areas on the pleural regions and face. The Oriental species, T. indica also has a curved stigmal vein, but this species has glabrate areas on the scutellum and medial incisions on the posterior tergite as in the Neotropical species. The remaining species of Tanaostigma have a straight stigmal vein, glabrate areas on the scutellum and medial incisions on the metasomal tergites.

Affinities. See under T. mulu.

Etymology. The species epithet 'ukumbusho' is Kiswahili (a widely spoken East African language) for 'memorial', and is chosen to honour the memory of John LaSalle. Noun in apposition.

Distribution. Kenya. Only known from Coast Province.

Biology. Unknown.

Habitat. Open canopy forest.

\section{Tanaostigmodes tambotis Prinsloo \& LaSalle, 1995}

(Figure 7(a-f))

Tanaostigmodes tambotis Prinsloo \& LaSalle, 1995, 8-11. Holotype $\circ$ SOUTH AFRICA, North West Province, Oskraal, 23 km NW Ga-Rankuwa, 25.30S 27.54E, i.1992, D. LeLagadec, ex galls on stems of Spirostachys africana (SANC).

Additional material. 2F, 2M: NAMIBIA, Tsumeb, Varianto, Elandshoek, 771 - SE 1917 Bc, 07.III.1999, leg. P.A. Basson, ex Spirostachys africana, Tanaostigmodes tambotis Prinsloo \& LaSalle 1995, det. S. van Noort 1999, SAM-HYM-P021102 (SAMC). 1M: TANZANIA, Mkomazi Game Reserve, Ibaya Hill, 03.58S 37.47E, 10 December 1995, S. van Noort, Acacia/ Combretum bushveld, sweep, SAM-HYM-P0014589 (SAMC).

Distribution. Namibia, South Africa, Tanzania.

Biology. A gregarious phytophagous gall former on Spirostachys africana (Tamboti) (Euphorbiaceae). 

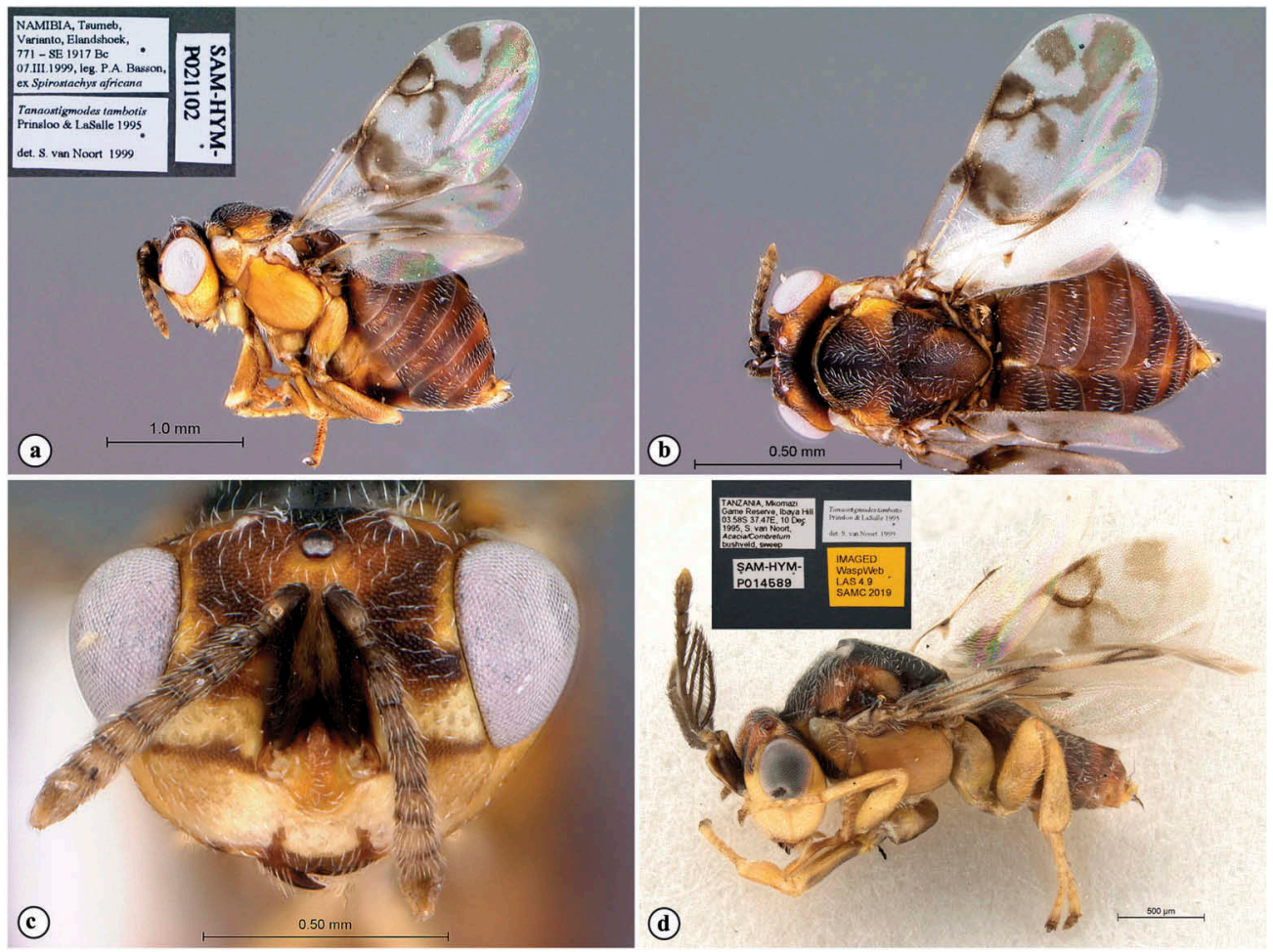

Figure 7. Tanaostigmodes tambotis female (a-c), male (d). (a) Habitus, lateral view (inset: data labels) (b) Habitus, dorsal view (c) Head, anterior view (d) Habitus, lateral view (inset: data labels).

Comments. Previously only known from South Africa, we here add Namibia and Tanzania as new country records. This species is likely to be far more widespread through east and southern Africa, conforming with the distribution of the host Tamboti tree. Spirostachys africana extends from Kwazulu-Natal (South Africa) in the south through Swaziland, Mozambique, Botswana, Zimbabwe, and Tanzania to southern Kenya; also present in northern Namibia and southern Angola (Mapaura \& Timberlake 2004; Setshogo 2005; Boon 2010; Palgrave 2015; Burrows et al. 2018).

\section{Discussion}

The New World species T. stanleyi was considered by LaSalle (1987) to be the most pleisomorphic member of the genus, even though this species possesses a number of autapomorphies including the squamiform setae and flattened funicle. This species, however, has a curved stigmal vein instead of the straight vein possessed by all other New World species and has no medial incision on the posterior margin of T2-T3, the latter two character states shared with the African species. All three African species do not have flattened funicle segments, suggesting that they form an even more basal clade within the genus.

Tanaostigma mulu is half the size of the other two species, and there is a possibility that this specimen is a dwarf of T. ukumbusho. Size can vary with environmental 
conditions, particularly food quality and abundance. However, in our opinion, there are strong enough character state differences, including a very different fore wing shape, disparate presence/abundance of setae forming the transverse band, and wing vein configuration that preclude this possibility. In addition, the differences in mesopleural surface sculpture and density of the white squamiform setae on all body parts are very distinct between these two species, beyond an expected variation as a result of size difference.

The family is begging for a comprehensive phylogenetic analysis to tease out potential convergence, possibly of the squamiform setae, and the modified setae on the fore wing. The morphologically similar genus Tanaostigmodes is most likely paraphyletic and a combined molecular and morphological phylogenetic appraisal would help place the Old and New World clades in an evolutionary context. Species richness of the Tanaostigmatidae is currently centred in the New World, but this may be a biased interpretation, based on lack of sufficient global species data.

\section{Acknowledgements}

Ezemvelo Wildlife is thanked for providing collecting permits. SvN was funded by South African NRF (National Research Foundation) grants: GUN 81139; GUN 98115. RSC thanks the director of ICIPE for her continuing support of our project on the biodiversity of insects, and gratefully acknowledges the ICIPE core funding provided by UK Aid from the Government of the United Kingdom; Swedish International Development Cooperation Agency (SIDA); the Swiss Agency for Development and Cooperation (SDC); Federal Ministry for Economic Cooperation and Development (BMZ), Germany, and the Kenyan Government.

\section{Disclosure statement}

No potential conflict of interest was reported by the authors.

\section{Funding}

This work was supported by the National Research Foundation [81139,98115].

\section{ORCID}

Simon van Noort (iD https://orcid.org/0000-0001-6930-9741

Robert S. Copeland (D) https://orcid.org/0000-0003-4865-5412

\section{References}

Arnett RH Jr., Samuelson GA, Nishida GM. 1993. The insect and spider collections of the world. 2nd ed. Flora and Fauna Handbook No. 11. Gainesville: Sandhill Crane Press; p. 310.

Boon R. 2010. Pooley's trees of Eastern South Africa - a complete guide. Durban: Flora \& Fauna Publications Trust. ISBN: 978-0-620-46019-4.

Bouček Z. 1988. Australasian Chalcidoidea (Hymenoptera). A biosystematic revision of genera of fourteen families, with a reclassification of species. Wallingford (Oxon): CAB International; Aberystwyth (Wales): Cambrian News Ltd; p. 832. 
Burrows JE, Burrows SM, Lötter MC, Schmidt E. 2018. Trees and shrubs, Mozambique. Cape Town: Publishing Print Matters (Pty) Ltd; p. 1124.

Eady RD. 1968. Some illustrations of microsculpture in Hymenoptera. Proc R Entomol Soc London (A). 43(4-6):66-72. doi:10.1111/j.1365-3032.1968.tb01029.x.

Fernandes GW, Martins RP, Tameirão-Neto E. 1987. Food web relationships involving Anadiplosis sp. galls (Diptera: Cecidomyiidae) on Machaerium aculeatum (Leguminosae). Revista Brasileria de Botanica. 10:117-123.

Gibson GAP. 1993. Superfamilies Mymarommatoidea and Chalcidoidea. In: Goulet H, Huber J, editors. Hymenoptera of the World: an identification guide to families. Ottawa (Canada): Research Branch, Agriculture Canada; p. 570-655, 668.

Gupta A, Joshi S. 2016. The first record of the genus Tanaostigma (Hymenoptera: Tanaostigmatidae) in the old world, with the description of a new species from India. Zootaxa. 4193(1):197-200. doi:10.11646/zootaxa.4193.1.13.

Harris RA. 1979. A glossary of surface sculpturing. California Dept Food Agric Occasional Papers Entomol. 28:1-31.

Howard LO. 1890. A new and remarkable encyrtid: is it parasitic? Insect Life. 3:1-147.

LaSalle J. 1987. New World Tanaostigmatidae (Hymenoptera, Chalcidoidea). Contrib Am Entomol Inst. 23(1):1-181.

LaSalle J. 1997. Chapter 19, Tanaostigmatidae. In: Gibson GAP, Huber JT, Woolley JB, editors. Annotated keys to the genera of Nearctic Chalcidoidea (Hymenoptera). Ottawa (Canada): National Research Council Research Press; p. 700-704, 794.

LaSalle J. 2005. Biology of gall inducers and evolution of gall induction in Chalcidoidea (Hymenoptera: Eulophidae, Eurytomidae, Pteromalidae, Tanaostigmatidae, Torymidae). In: Raman A, Schaefer CW, Withers TM, editors. Biology, ecology, and evolution of gall-inducing arthropods. Enfield (New Hampshire): Science Publishers, Inc.; p. 507-537.

LaSalle J, Noyes JS. 1985. New family placement for the genus Cynipencyrtus (Hymenoptera, Chalcidoidea, Tanaostigmatidae). J N Y Entomol Soc. 93(4):1261-1264.

Lateef SS. 1977. A new Hymenopteran pest (Tanaostigmodes sp. (Hymenoptera: Tanaostigmatidae) recorded on pigeon pea (Cajanus cajan Millsp) at ICRISAT, Hyderabad, India. Trop Grains Bull. 7:6.

Lateef SS, Reed W, LaSalle J. 1985. Tanaostigmodes cajaninae LaSalle, sp. n. (Hymenoptera: Tanaostigmatidae), a potential pest of pigeonpea in India. Bull Entomol Res. 75:305-313. doi:10.1017/S0007485300014395.

Mapaura A, Timberlake J, editors. 2004. A checklist of Zimbabwean vascular plants Southern African Botanical Diversity Network Report No. 33. Pretoria and Harare: Sabonet.

Noyes JS. 2019. Universal Chalcidoidea Database. World Wide Web electronic publication. [accessed 2019 Mar 20]. http://www.nhm.ac.uk/chalcidoids.

Palgrave KC. 2015. Trees of Southern Africa. Cape Town: Penguin Random House South Africa; p. 1212. ISBN: 9781920572754.

Prinsloo GL, LaSalle J. 1995. A new species of tanaostigmatid (Hymenoptera: Chalcidoidea) from South Africa, that forms galls on tamboti. Afr Entomol. 3:7-11.

Risbec J. 1955. Chalcidoïdes et proctotrupoïdes Africaines. Bull de l'Institut Français d'Afrique Noire. 17:533-580.

Seltmann KC, Yoder MJ, Mikó I, Forshage M, Bertone MA, Agosti D, Austin AD, Balhoff JP, Borowiec ML, Brady SG, et al. 2012. A hymenopterists' guide to the Hymenoptera Anatomy Ontology: utility, clarification, and future directions. J Hymenoptera Res. 27:67-88. doi:10.3897/ jhr.27.2961.

Setshogo MP. 2005. Preliminary checklist of the plants of Botswana. Pretoria and Gaborone: Sabonet. Sabonet Report no. 37.

Tachikawa T. 1973. Discovery of the hosts of Cynipencyrtus bicolor Ishii and Microterys tarumensis Tachikawa (Hymenoptera: ChalcidideaEncyrtidae). Trans Shikoku Entomol Soc. 11(4):133-134.

Tachikawa T. 1978. A note on the genus Cynipencyrtus Ishii (Hymenoptera: Chalcidoidea: Encyrtidae). Trans Shikoku Entomol Soc. 14(1-2):69-71.

Trjapitzin VA. 1977. New genera and species of parasitic Hymenoptera of the family Encyrtidae (Hymenoptera: Chalcidoidea). Folia Entomologica Hungarica. 30:153-166. 